\title{
Amnesia, flashbacks, nightmares, and dissociation in aging concentration camp survivors
}

Citation for published version (APA):

Merckelbach, H. L. G. J., Dekkers, T., Wessel, I., \& Roefs, A. J. (2003). Amnesia, flashbacks, nightmares, and dissociation in aging concentration camp survivors. Behaviour Research and Therapy, 41(3), 351360. https://doi.org/10.1016/S0005-7967(02)00019-0

Document status and date:

Published: 01/01/2003

DOI:

10.1016/S0005-7967(02)00019-0

Document Version:

Publisher's PDF, also known as Version of record

\section{Please check the document version of this publication:}

- A submitted manuscript is the version of the article upon submission and before peer-review. There can be important differences between the submitted version and the official published version of record.

People interested in the research are advised to contact the author for the final version of the publication, or visit the DOI to the publisher's website.

- The final author version and the galley proof are versions of the publication after peer review.

- The final published version features the final layout of the paper including the volume, issue and page numbers.

Link to publication

\footnotetext{
General rights rights.

- You may freely distribute the URL identifying the publication in the public portal. please follow below link for the End User Agreement:

www.umlib.nl/taverne-license

Take down policy

If you believe that this document breaches copyright please contact us at:

repository@maastrichtuniversity.nl

providing details and we will investigate your claim.
}

Copyright and moral rights for the publications made accessible in the public portal are retained by the authors and/or other copyright owners and it is a condition of accessing publications that users recognise and abide by the legal requirements associated with these

- Users may download and print one copy of any publication from the public portal for the purpose of private study or research.

- You may not further distribute the material or use it for any profit-making activity or commercial gain

If the publication is distributed under the terms of Article $25 \mathrm{fa}$ of the Dutch Copyright Act, indicated by the "Taverne" license above, 


\title{
Amnesia, flashbacks, nightmares, and dissociation in aging concentration camp survivors
}

\author{
Harald Merckelbach *, Theo Dekkers, Ineke Wessel, Anne Roefs \\ Department of Experimental Psychology and Faculty of Law, University of Maastricht, PO Box 616, 6200 MD, \\ Maastricht, The Netherlands
}

Accepted 25 January 2002

\begin{abstract}
The current study examined to what extent war memories of Dutch survivors of Japanese/Indonesian concentration camps display characteristics that are often believed to be typical for traumatic memories. Twenty-nine survivors were interviewed about amnesia, flashbacks, nightmares and the sensory quality of their most upsetting war memories. In addition, they completed self-report scales measuring post-traumatic stress symptoms and dissociation. In contrast to prevailing notions, amnesia, flashbacks and nightmares were not typical for this sample. Neither were traumatic memories characterized by a particularly strong sensory loading. Post-traumatic stress symptoms were not related to dissociative experiences. At least for this group of aging survivors, it appears that the pathogenic potential of traumatic memories has more to do with their extremely aversive content than with a qualitatively different type of organization of these memories.
\end{abstract}

(C) 2002 Elsevier Science Ltd. All rights reserved.

\section{Introduction}

Some authors assume that traumatic memories and memories of non-traumatic events differ not only in their emotional content, but also in the way they are organized (see for critical reviews, Porter \& Birt, 2001; Shobe \& Kihlstrom, 1997). It is their qualitatively distinct organization that is thought to constitute the "apparent uniqueness of traumatic memories" (Van der Kolk, 1996, p. 282; see also Van der Kolk \& Fisler, 1995). According to this view, many trauma survivors suffer from autobiographical memory disturbances (e.g. psychogenic or dissociative amnesia) and intrusions (e.g. flashbacks and nightmares) that would possess strong sensory and photographic

\footnotetext{
* Corresponding author. Tel.: +31-433-881-945; fax: +31-433-881-908.

E-mail address: h.merckelbach@psychology.unimaas.nl (H. Merckelbach).
} 
qualities. This asymmetry between poor narrative memory and intrusions is often referred to as dissociative fragmentation, which is assumed to be the vehicle behind trauma-related psychopathology (Van der Kolk, 1996).

Although the "uniqueness view" on traumatic memories has gained popularity among clinicians, some findings represent anomalies for this view. For example, Kuch and Cox (1992) noted that holocaust survivors rarely report psychogenic amnesia for their horrifying war experiences. As another example, several authors have questioned the sensory qualities that are often ascribed to flashbacks. They argue that flashbacks might be top-down reconstructions rather than bottom-up replicas of the traumatic event (Bryant \& Harvey, 1998; Frankel, 1994, 1996; Lipinski \& Pope, 1994; Merckelbach, Muris, Horselenberg, \& Rassin, 1998). A similar point has been raised with regard to the alleged photographic qualities of traumatic nightmares (Brooks Brenneis, 1994; Mazzoni \& Loftus, 1998). Furthermore, some studies found the correlations between trauma intensity, dissociative experiences, and Post Traumatic Stress Disorder (PTSD) symptoms to be far from perfect (e.g., Yehuda et al., 1996).

The current study sought to test the assumptions underlying the uniqueness view in a sample of Dutch concentration camp survivors. They were asked whether they had ever experienced periods during which important aspects of their trauma were not or less accessible and the extent to which they suffered from intrusive flashbacks and/or nightmares. We also interviewed survivors about the sensory qualities of their traumatic memories. Finally, we examined whether in this group, dissociative experiences and trauma-related distress go hand in hand, as the uniqueness view would lead one to expect. Our study focused on concentration camp survivors because there can be no doubt that during their pre-teen years, these individuals had been exposed to circumstances that the fourth edition of the Diagnostic and Statistical Manual of Mental Disorders (DSM-IV, American Psychiatric Association, 1994, p. 27) would qualify as traumatic, i.e. experiencing or witnessing "an event or events that involved actual or threatened death or serious injury, or a threat to the physical integrity of self or others." Thus, self-reports of these individuals about their traumatic memories and psychological symptoms offer an opportunity to evaluate the merits of the uniqueness view.

\section{Method}

\subsection{Participants}

Volunteers were 29 Dutch concentration camp survivors (15 women) who were all in treatment for their war-related psychiatric symptoms. They were recruited from a medical practice specialised in the somatic and psychiatric treatment of Dutch civilians who suffer from the long-term after-effects of World War II. At the time this study was conducted (end of 1998), the mean age of the participants was 61 years (range: 55-71 years). Seventeen participants (58\%) had a mixed Asian-Caucasian (i.e. Indo-European) background and 12 (41\%) had a Caucasian (i.e. European) background. Mean years of education was 11 years (range: 4-20 years). At the time of the study, participants had been in treatment for about 22 months (range 4-36 months). Fifteen participants (52\%) had a DSM-IV diagnosed Post Traumatic Stress Disorder (PTSD), while the remaining participants suffered from Major Depressive Disorder, Dysthymia, Eating Disorder, Bipolar Dis- 
order or a different Anxiety Disorder than PTSD. None of the participants had a diagnosis of schizophrenia or suffered from a major neurological illness. Eleven participants (38\%) received psychotropic medication for their psychiatric complaints.

\subsection{Historical background}

Until 1949, Indonesia was a Dutch colony (Dutch East Indies). In 1942, the Japanese invaded the Dutch East Indies. Within days, the Dutch army was defeated and soldiers were imprisoned. Most European Dutch civilians in the Dutch East Indies lost their homes and properties and were imprisoned in separate concentration camps. In these camps, conditions were so bad, "that death rates were even higher than in the prisoner-of-war camps. Mortality among male prisoners was $20 \%$, among women $10 \%$ and among children 5\%" (Bramsen, 1995, p. 6). After the Japanese capitulation, Indonesian nationalists immediately launched a campaign for independence, which involved acts of aggression and terror against European and Indo-European Dutch civilians of whom many were imprisoned for a second time. This situation continued until 1949 when Indonesia became independent and Dutch citizens were repatriated (Bramsen, 1995). Twenty-two (76\%) participants in the current study had been imprisoned in Japanese concentration camps between 1942 and 1945, while seven participants had been imprisoned during the 1945-1949 period.

\subsection{Interview}

A trained therapist (Th. D.) who knew each survivor's background very well conducted a structured interview consisting of a series of open-ended questions. Survivors' responses were written down and subsequently coded by an independent judge who was blind with respect to the purpose of the current study. In order to establish interrater agreement, a second judge scored randomly selected protocols of five patients. Overall agreement was $87.2 \%$.

The interview started with the interviewer asking the survivor to pinpoint the most adverse war episode he or she had experienced. Next, the survivor was asked whether his/her memories of this episode consisted of visual images, auditory images, olfactory sensations and/or bodily sensations. Similar questions were asked about neutral childhood episodes. For each item, answers were coded as "yes", "no" or "I don't know".

Survivors were also asked whether their most traumatic memories had been stable across time. A similar question was asked about their neutral childhood memories. Again, answers to these items were coded as "yes", "no", or I don't know". Survivors were then asked whether the accessibility of their most traumatic war memories had ever changed over the course of their life. Responses were coded as "yes, although the memories were there, I tried hard not to think of them"; "yes, the memories were completely gone"; "no, the memories have always been accessible" or "I don't know".

Next, survivors were asked to what extent they suffered from flashbacks. They were not provided with a formal definition of this concept. Answers were coded as "never", "less than once every month", "monthly", "weekly", "2-4 times a week", or "daily". If survivors indicated that they did experience flashbacks, they were asked whether flashbacks contained visual images, auditory images, olfactory sensations and/or bodily sensations. Responses to these items were coded as "yes", "no" or "I don't know". They were also asked whether the content of the flash- 
backs corresponded with the traumatic war events (answers were coded as "yes", "no", "sometimes" or "I don't know'). Similar questions were asked with respect to survivors' nightmares about their most adverse war experiences.

\subsection{Questionnaires}

Participants completed at their own home the Impact of Event Scale (IES) (Horowitz, Wilner, \& Alvarez, 1979), the self-report version of the PTSD Symptom Scale (PSS) (Foa, Riggs, Dancu, \& Rothbaum, 1993), and the Dissociative Experiences Scale (DES) (Bernstein \& Putnam, 1986).

The IES consists of 15 statements (e.g. "I had dreams about it") that tap traumatic intrusions and avoidance of trauma-related thoughts. Using 4-point frequency scales $(0=$ not at all; $1=$ rarely; $3=$ sometimes; $5=$ often), respondents indicate to what extent these statements apply to them over the past week. Although the IES is not a measure of PTSD per se, it is a psychometrically sound index of trauma-related distress (e.g. S. Joseph, 2000). In the current study, scores were summed to obtain total scores for the 7-item intrusion factor (Cronbach alpha $=0.89$ ) and the 8-item avoidance factor (Cronbach alpha $=0.87$ ).

The PSS (Cronbach alpha $=0.90$ ) is a 17-item self-report instrument to measure the presence and severity of PTSD symptoms in traumatized individuals. Items (e.g. "Have you had upsetting thoughts or images about the traumatic event that came into your head when you didn't want them to") pertain to PTSD symptoms listed by the DSM. Using a 4-point scale (0=not at all; $3=$ very $m u c h$ ), respondents indicate to what extent each symptom was present during the last week. Scores are summed to obtain a total severity score with higher scores indicating higher severity. Foa et al. (1993) summarize evidence to support the reliability and validity of the PSS.

The DES (Cronbach alpha=0.91) is a widely used self-report scale containing 28 items that describe dissociative phenomena such as disturbances in memory, awareness, and identity. An illustrative item is: "Some people have the experience of driving a car and suddenly realizing that they don't remember what has happened during all or part of the trip. Mark the line to show what percentage of the time this happens to you". Participants indicate on $100-\mathrm{mm}$ visual analog scales the frequency with which they experience each dissociative phenomenon. Scores are averaged to obtain a mean DES scores. The DES possesses excellent internal consistency and testretest stability (Van IJzendoorn \& Schuengel, 1996).

\section{Results}

\subsection{Sensory qualities and psychogenic amnesia}

Table 1 shows the number of participants who reported visual, auditory, olfactory and/or bodily details for both categories of memories. It is not the case that traumatic memories had a stronger sensory loading than neutral memories. Sign Tests indicated that the two memory categories did not differ in this respect $(p>0.20)$. The lower part of Table 1 shows the frequency of self-reported experiences that might be construed as evidence for psychogenic amnesia, which following the DSM, was defined as abnormal forgetting of important aspects of the trauma. All $29(100 \%)$ participants felt that their most traumatic memories had been stable across their lives, while 22 
Table 1

Sensory qualities attributed to traumatic and neutral memories by concentration camp survivors $(N=29)$

\begin{tabular}{lll}
\hline & Traumatic memories $n(\%)$ & Neutral memories $n(\%)$ \\
\hline Visual & $25(86)$ & $26(90)$ \\
Auditory & $19(66)$ & $21(72)$ \\
Olfactory & $18(62)$ & $16(55)$ \\
Bodily & $16(55)$ & $18(62)$ \\
Stabilitya & $29(100)$ & $22(76)$ \\
Accessibility: & $12(41)$ & \\
Memorics were always accessible & $11(38)$ & \\
I tried hard not to think of them & $1(3)$ & \\
Memories were completely gone & $5(17)$ & \\
I don't know & \\
\hline
\end{tabular}

${ }^{\mathrm{a}} p<0.05$ (Sign Test).

$(76 \%)$ of them said that neutral memories had been stable across time (Sign Test: $p=0.02)$. This suggests that traumatic memories were more stable than neutral memories. Similarly, 12 participants (41\%) felt that their traumatic memories had always been accessible, while 11 of them (38\%) indicated that their had been episodes during which they tried hard not to think of these memories. Only one participant reported to have experienced episodes in which traumatic memories were inaccessible. This survivor was born in 1939 and said that he had no memories of the first 8 years of his life, including the traumatic war period. He had a PTSD diagnosis and a history of drug abuse.

\subsection{Flashbacks and nightmares}

Table 2 shows self-reported frequency of flashbacks and nightmares. As can be seen, a majority of the participants (63 and $76 \%$, respectively) said that these phenomena occurred with a frequency of once every month or less. Frequency categories were scored (anchors: $0=n e v e r$ and $5=$ daily) and a paired samples $t$-test showed that there were no differences in frequency distribution for flashbacks and nightmares: $t(28)<1.0$. Flashbacks were more often accorded the status of mirroring the traumatic event than were nightmares (Sign Test: $p=0.04$ ). On the other hand, the two types of intrusive imagery were comparable with regard to the sensory characteristics attributed to them (all $p$ 's $>0.20$ ).

\subsection{Dissociative experiences and PSTD-related symptoms}

Table 3 shows mean scores on IES-subscales, PSS and DES. The average total IES score (IESintrusion plus IES-avoidance) is well above the clinical cutoff score of 35 recommended for PTSD (i.e. S. Joseph, 2000. As a matter of fact, 19 survivors (65\%) had total IES score that exceeded this cutoff. Mean PSS score of our sample came close to PSS scores that have been reported for other groups of victims (e.g. Griffin, Resick, \& Mechanic, 1997). The mean DES score in our sample was comparable to scores that have been obtained for nonclinical samples (e.g., Van 
Table 2

Frequency of flashbacks and nightmares reported by concentration camp survivors $(N=29)$

\begin{tabular}{lll} 
& Flashbacks $n(\%)$ & Nightmares $n(\%)$ \\
\hline Frequency: & & \\
Never & $8(28)$ & $9(31)$ \\
Less than once every month & $6(21)$ & $6(21)$ \\
Monthly & $4(14)$ & $7(24)$ \\
Weekly & $6(21)$ & $2(7)$ \\
2-4 times a week & $3(10)$ & $5(17)$ \\
daily & $2(7)$ & $0(0)$ \\
Similarity to the trauma: & & $7(24)$ \\
Yes & $21(72)$ & $13(45)$ \\
No & $0(0)$ & $9(31)$ \\
I'm not sure/does not apply to me & $8(28)$ & \\
\hline Sensory characteristics: & & $20(69)$ \\
Visual & $20(69)$ & $13(45)$ \\
Auditory & $13(45)$ & $9(31)$ \\
Olfactory & $10(35)$ & $20(69)$ \\
Bodily & $12(41)$ & \\
\hline
\end{tabular}

a $p<0.05$ (Sign Test).

Table 3

Means scores (and standard deviations) on IES-intrusion, IES-avoidance, PSS, and DES and Pearson-product-moment correlations between these measures $(N=29){ }^{\mathrm{a}}$

\begin{tabular}{lllll}
\hline & Mean (SD) & IES-intrusion & IES-avoidance & PSS \\
\hline IES-intrusion & $20.2(10.3)$ & & & \\
IES-avoidance & $20.6(11.6)$ & $0.90^{\mathrm{b}}$ & & \\
PSS & $23.0(11.9)$ & $0.75^{\mathrm{b}}$ & $0.72^{\mathrm{b}}$ & 0.22 \\
DES & $20.3(13.6)$ & 0.03 & 0.13 & 0.13 \\
\hline
\end{tabular}

a Abbreviations: IES-intrusion, intrusion subscale of the Impact of Event Scale; IES-avoidance, avoidance subscale of the Impact of Event Scale; PSS, PTSD Symptom Scale; DES, Dissociative Experiences Scale

${ }^{\mathrm{b}} p<0.01$

IJzendoorn \& Schuengel, 1996; Merckelbach, Muris, Rassin, \& Horselenberg, 2000). In line with this, only seven participants $(21 \%)$ had a DES score above the clinical cutoff of 30 recommended by Putnam et al. (1996).

Table 3 shows Pearson correlations between PTSD-related measures (IES-intrusion, IES-avoidance, PSS) and dissociative experiences (DES). As can be seen, correlations among PTSD-related measures were all highly significant $(r>0.72, p<0.001)$. In contrast, correlations between PTSDrelated measures and DES all failed to attain significance $(r<0.22, p>0.26)$. 


\section{Discussion}

\subsection{Do traumatic memories have special properties?}

Over the past few years, a number of authors (e.g. Chu, Frey, Ganzel, \& Matthews, 1999; Van der Kolk, 1994, 1996) have proposed that traumatic memory has special properties reflecting a distinct organization. For example, Van der Kolk (1994; p. 258) argued that "trauma interferes with declarative memory (i.e. conscious recall of experience), but does not inhibit implicit or nondeclarative memory, the memory system that controls conditioned emotional responses, skills and habits, and sensorimotor sensations related to experience". The current findings show that this view does not provide an adequate portrayal of the way survivors in our study experienced their traumatic memories. Only one survivor reported mnemonic experiences that might be construed as evidence for psychogenic amnesia (i.e. poor conscious recall of traumatic experiences), but in this case the question arises whether drug abuse contributed to poor autobiographical memories of the traumatic episode. In addition, no evidence was found to suggest that traumatic memories possess more sensory features than do neutral memories. Furthermore, only a minority of the survivors reported to experience flashbacks and nightmares on a daily basis. And finally, dissociative experiences, which are often seen as hallmark features of memory fragmentation (e.g. Van der Kolk \& Fisler, 1995), failed to correlate with measures of PTSD-related distress.

One could counter that participants in the current study were aging survivors who had been exposed to traumatic events decades ago. Perhaps, then, their traumatic memories had acquired a normal organization over the years. On the other hand, our sample was certainly not free of psychopathology. Half of them suffered from PTSD and mean scores on IES and PSS of the total sample were highly comparable to scores that have been reported for more recently traumatised people (e.g. rape victims; see Griffin et al,, 1997 or former political prisoners; see Maercker \& Schutzwohl, 1997). Apparently, then, severe trauma-related psychopathology may exist in the absence of features that are thought to be typical for the qualitatively distinct form of traumatic memories.

\subsection{Psychogenic amnesia}

Only one survivor said that he had experienced periods during which his traumatic memories had been inaccessible. Also, survivors indicated that their most adverse war memories had been more stable across their lives than their neutral childhood memories. To the extent that such selfreports bear relevance to psychogenic amnesia, they suggest that this phenomenon is rare among aging concentration camp survivors. This conclusion fits well with previous studies noting that the lifetime prevalence of psychogenic amnesia is relatively low in concentration camp survivors and former political prisoners (e.g., Kuch \& Cox, 1992; Maercker \& Schutzwohl, 1997; Yehuda et al., 1996). The relative absence of psychogenic amnesia in our sample is in line with two indepth studies (Schelach \& Nachson, 2001; Wagenaar \& Groeneweg, 1990) reporting that autobiographical forgetting in concentration camp survivors only rarely exceeds the level of ordinary forgetfulness. Taken together, our findings as wells as those of many other authors (e.g., Kuch \& Cox, 1992; Porter \& Birt, 2001; Schelach \& Nachson, 2001; Yehuda et al., 1996) run counter to claims that amnesia is a common consequence of exposure to severe stress (R. Joseph, 2000) and 
is highly prevalent among WWII victims (e.g. Karon \& Widener, 1997; see also Lilienfeld \& Loftus, 1998).

Although we found psychogenic amnesia to be rare among concentration camp survivors, there was a nontrivial minority of survivors $(38 \%)$ who said that there had been periods in their lives during which accessibility of their war memories had changed due to thought suppression attempts. This is reminiscent of Melchert and Parker's (1997) finding that people with traumatic childhood memories often refer to intentional avoidance of these memories when they report episodes of poor autobiographical memory.

\subsection{Flashbacks and nightmares}

We found relatively low frequencies of daily flashbacks in our sample and this underlines the observation by Kuch and Cox (1992) that in contrast to Vietnam veterans, concentration camp survivors rarely report feelings of recurrence. Kuch and Cox speculated that this discrepancy might have something to do with comorbid substance abuse in Vietnam veterans, a suggestion that is not implausible if one considers the historical background of the concept of "flashbacks". Thus Frankel (1994) noted that this phenomenon has been extensively described in the literature on hallucinogenic drugs.

Participants who experienced flashbacks all felt that they were accurate relivings of the traumatic experience. On the other hand, many of these survivors said that their flashbacks contained no auditory, olfactory and/or bodily details. This might imply that their flashbacks were reminiscences rather than full-blown recurrences (e.g. Frankel, 1994; VanOyen Witvliet, 1997). Much the same is true for participants' reports of nightmares. However, here, a considerable percentage of survivors $(45 \%)$ denied that their nightmares possessed historical accuracy. This accords well with a study by Esposito, Benitez, and Mellman (1999) who found that the majority of their PTSD diagnosed Vietnam veterans reported distorted elements in their dream content. All in all, the present study obtained little or no support for the idea that flashbacks and nightmares of the survivors in our sample had become fixed in the mind, unaltered by the passage of time or by the intervention of subsequent experience (Van der Kolk, 1996).

One could argue that the relatively low self-reported frequency of flashbacks and nightmares in the current study is due to therapy, the passage of time, and/or the unreliability of self-reports. Admittedly, prospective data on these intrusive phenomena would have been more informative (e.g., Mellman David, Bustamante, Torres, \& Fins, 2001). However, at the very least, our findings suggest that flashbacks and nightmares may subside without other PTSD- related symptoms going away.

\subsection{Dissociation}

In the literature, there has been some discussion about whether PTSD should be conceptualised as an anxiety or a dissociative disorder (e.g. Brett, 1993). Our results show that PTSD-related symptoms and dissociative experiences do not necessarily overlap with each other. Hence, they argue against the view that dissociation is a core feature of PTSD (e.g. Gershuny \& Thayer, 1999). Interestingly, in their sample of aging Holocaust victims, Yehuda and co-workers (1996) also obtained evidence that PTSD and dissociation are separate constructs. Of course, the fre- 
quency of dissociative experiences may decline with age (Walker, Gregory, Oakley, Bloch, \& Gardner, 1996). Nevertheless, our results and those of Yehuda et al. (1996) demonstrate that PTSD-related distress does not critically depend on high rates of dissociative experiences.

\subsection{Conclusion}

The distinct qualities often ascribed to traumatic memories do not provide an adequate description of the memories of our participants. This is not to say that the "uniqueness view" on traumatic memories has no heuristic value for other categories of traumatised people. Thus, it might well be the case that certain types of trauma (e.g. child sexual abuse) produce a constellation of phenomena that are accurately captured by this view (but see Shobe \& Kihlstrom, 1997). Given the fact that the uniqueness view has gained popularity over the past few years and bears strong relevance to important diagnostic and treatment issues, further attempts to test its limits and empirical credibility for various traumatised groups are required.

\section{Acknowledgements}

This study was supported by a grant of the Dutch Council for Scientific Research (NWO; 575 29-001) awarded to Dr. H Merckelbach. The authors thank Dr Loes Akkermans for her help in the data collection.

\section{References}

American Psychiatric Association (1994). Diagnostic and statistical manual of mental disorders (4th ed.). Washington, DC: Author.

Bernstein, E. M., \& Putnam, F. W. (1986). Development, reliability, and validity of a dissociation scale. Journal of Nervous and Mental Disease, 174, 727-735.

Bramsen, I. (1995). The long-term psychological adjustment of World War II survivors in The Netherlands. Delft: Eburon Press.

Brett, E. A. (1993). Classifications of PTSD in DSM-IV: Anxiety disorder, dissociative disorder or stress disorder? In J. R. T. Davidson, \& E. B. Foa (Eds.), Posttraumatic stress disorder: PTSD and beyond (pp. 191-204). Washington DC: American Psychiatric Press.

Brooks Brenneis, C. (1994), Can early childhood trauma be reconstructed from dreams? On the relation of dreams to trauma. Psychoanalytic Psychology, 11, 429-447.

Bryant, R. A., \& Harvey, A. G. (1998). Traumatic memories and pseudomemories in posttraumatic stress disorder. Applied Cognitive Psychology, 12, 81-88.

Chu, J. A., Frey, L. M., Ganzel, B. L., \& Matthews, J. A. (1999). Memories of childhood abuse: Dissociation, amnesia, and corroboration. American Journal of Psychiatry, 156, 749-755.

Esposito, K., Benitez, A., Barza, L., \& Mellman, T. (1999). Evaluation of dream content in combat-related PTSD. Journal of Traumatic Stress, 12, 681-687.

Foa, E. B., Riggs, D. S., Dancu, C. V., \& Rothbaum, B. O. (1993). Reliability and validity of a brief instrument for assessing Post Traumatic Stress Disorder. Journal of Traumatic Stress, 6, 454-473.

Frankel, F. H. (1994). The concept of flashbacks in historical perspective. International Journal of Clinical and Experimental Hypnosis, 42, 321-336.

Frankel, F. H. (1996). Dissociation; The clinical realities. American Journal of Psychiatry, 153, 64-70.

Gershuny, B. S., \& Thayer, J. F. (1999). Relations among psychological trauma, dissociative phenomena, and traumarelated distress: A review and integration. Clinical Psychology Review, 19, 631-657. 
Griffin, M. G., Resick, P. A., \& Mechanic, M. B. (1997). Objective assessment of peritraumatic dissociation: Psychophysiological indicators. American Journal of Psychiatry, 154, 1081-1088.

Horowitz, M., Wilner, N., \& Alvarez, W. (1979). Impact of Event Scale: A measure of subjective stress. Psychosomatic Medicine, 4I, 209-218.

Joseph, R. (2000). The neurology of traumatic dissociative amnesia: Commentary and literature review. Child Abuse and Neglect, 23, 715-727.

Joseph, S. (2000). Psychometric evaluation of Horowitz's impact of event scale: A review. Journal of Traumatic Stress, 13, 101-113.

Karon, B. P., \& Widener, A. J. (1997), Repressed memories and World War II: Lest we forget. Professional Psychology: Research and Practice, 28, 338-340.

Kuch, K., \& Cox, B. J. (1992). Symptoms of PTSD in 124 survivors of the Holocaust. American Journal of Psychiatry, $149,337-340$.

Lilienfeld, S. O., \& Loftus, E. F. (1998). Repressed memories and World War II: Some cautionary notes. Professional Psychology: Research and Practice, 29, 471-475.

Lipinski, J. F., \& Pope, H. G. (1994). Do flashbacks represent obsessional imagery? Comprehensive Psychiatry, 35 , $245-247$.

Maercker, A., \& Schutzwohl, M. (1997). Long-term effects of political imprisonment: A group comparison study. Psychiatry \& Psychiatric Epidemiology, 32, 435-442.

Mazzoni, G. L., \& Loftus, E. F. (1998). Dream interpretation can change beliefs about the past. Psychotherapy, 35, 177-186.

Melchert, T. P., \& Parker, R. L. (1997). Different forms of childhood abuse and memory. Child Abuse and Neglect, $21,125-135$.

Mellman, T. A., David, D., Bustamente, V., Torres, J., \& Fins, A. (2001). Dreams in the acute aftermath of trauma and their relationship to PTSD. Journal of Tratumatic Stress, 14, 241-247.

Merckelbach, H., Muris, P., Horselenberg, R., \& Rassin, E. (1998). Traumatic intrusions as 'worse case scenario's'. Behaviour Research and Therapy, 36, 1075-1079.

Merckelbach, H., Muris, P., Rassin, E., \& Horselenberg, R. (2000). Dissociative experiences and interrogative suggestibility in college students. Personality and Individual Differences, 29, 1133-1140.

Porter, S., \& Birt, A. R. (2001). Is traumatic memory special? A comparison of traumatic memory characteristics with memory for other emotional life experiences. Applied Cognitive Psychology, 15, 1-17.

Putnam, F. W., Carlson, E. B., Ross, C. A., Anderson, G., Clark, P., Torem, M., Bowman, E. S., Coons, Ph., Chu, J., Dill, D. L., Loewenstein, R. J., \& Braun, B. G. (1996). Patterns of dissociation in clinical and nonclinical samples. Journal of Nervous and Mental Disease, 184, 673-679.

Schelach, L., \& Nachson, I. (2001). Memory of Auschwitz survivors. Applied Cognitive Psychology, 15, 119-132.

Shobe, K. K., \& Kihlstrom, J, F. (1997). Is traumatic memory special? Current Directions in Psychological Science, $6,70-74$.

Van der Kolk, B. A. (1994). The body keeps the score: Memory and the evolving psychobiology of posttraumatic stress. Harvard Review of Psychiatry, 1, 253-265.

Van der Kolk, B. A. (1996). Trauma and memory. In B. A. Van der Kolk, A. C. McFarlane, \& L. Weisaeth (Eds.), Traumatic stress; The effects of overwhelming experience on mind, body, and society (pp. 279-302). New York: Guilford.

Van der Kolk, B. A., \& Fisler, R. (1995). Dissociation and the fragmentary nature of traumatic memories: Overview and exploratory study. Journal of Traumatic Stress, 8, 505-525.

Van IJzendoorn, M. H., \& Schuengel, C. (1996). The measurement of dissociation in normal and clinical populations; Meta-analytic validation of the Dissociative Experiences Scale (DES). Clinical Psychology Review, 16, 365-382.

VanOyen Witvliet, C. (1997). Traumatic intrusive imagery as an emotional memory phenomenon: A review of research and explanatory information processing theories, Clinical Psychology Review, 17, 509-536.

Wagenaar, W. A., \& Groeneweg, J. (1990). The memory of concentration camp survivors. Applied Cognitive Psychology, 4, 77-87.

Walker, R., Gregory, J., Okaley, S., Bloch, R., \& Gardner, M. (1996). Reduction in dissociation due to aging and cognitive deficit. Comprehensive Psychiatry, 37, 31-36.

Yehuda, R., Elkin, A., Binder-Brynes, K., Kahana, B., Southwick, S. M., Schmeidler, J., \& Giller, E. L. (1996). Dissociation in aging Holocaust survivors. American Journal of Psychiatry, 153, 935-940. 